\title{
High hydrostatic pressure induces apoptosis of retinal ganglion cells via regulation of the NGF signalling pathway
}

\author{
HONGJI LIU ${ }^{1 *}$, WEI WANG ${ }^{2 *}$, XIANG LI $^{3}, \mathrm{CHAO} \mathrm{HUANG}^{4}$, \\ ZONGDUAN ZHANG ${ }^{5}$, MINGYUE YUAN ${ }^{1}$ and XIANGYU LI ${ }^{1}$
}

\author{
${ }^{1}$ College of Ophthalmology, Chengdu University of Traditional Chinese Medicine, Chengdu, Sichuan 610072; \\ ${ }^{2}$ Department of Ophthalmology, Kunming Municipal Hospital of Traditional Chinese Medicine, Kunming, Yunnan 646000; \\ ${ }^{3}$ Department of Ophthalmology, Hospital of Chengdu University of Traditional Chinese Medicine, Chengdu, Sichuan 610072; \\ ${ }^{4}$ Central Laboratory, Shenzhen Bao'an People's Hospital Affiliated to Southern Medical University, Shenzhen, \\ Guangdong 518100; ${ }^{5}$ Department of Ophthalmology, The Affiliated Eye Hospital of \\ Wenzhou Medical University, Wenzhou, Zhejiang 325027, P.R. China
}

Received July 17, 2018; Accepted April 2, 2019

DOI: $10.3892 / \mathrm{mmr} .2019 .10206$

\begin{abstract}
High pressure is the most important factor inducing retinal ganglion cell (RGC) apoptosis. However, the underlying mechanisms remain obscure. The present study investigated the effects of different levels of hydrostatic pressure (HP) on RGCs and the potential mechanisms involved. Primary cultured rat RGCs were exposed to five levels of HP $(0,20,40,60$ and $80 \mathrm{mmHg})$ for $24 \mathrm{~h}$. Morphological changes in RGCs were observed. The viability and apoptosis rate of RGCs were detected using a Cell Counting Kit- 8 assay and Annexin V-fluorescein isothiocyanate/propidium iodide flow cytometry, respectively. Western blotting, reverse transcription-quantitative polymerase chain reaction and immunofluorescence were used to detect the expression and mRNA levels of nerve growth factor (NGF), protein kinase B (AKT), apoptosis signal-regulating kinase 1 (ASK1), forkhead box O1 (FoxO1) and cAMP response element binding protein (CREB). In the 0- and 20-mmHg groups, there were no apoptotic morphological changes. In the $40 \mathrm{mmHg}$ group, parts of the cell were shrunken or disrupted. In the $60 \mathrm{mmHg}$ group, neurite extension was weakened and parts of the cells were disintegrating or dying. In the $80 \mathrm{mmHg}$ group, the internal structures of the cells were not visible at all. The apoptosis rates of RGCs were significantly higher and the viability rates
\end{abstract}

Correspondence to: Professor Xiang Li, Department of Ophthalmology, Hospital of Chengdu University of Traditional Chinese Medicine, 39 Shi-er-qiao Road, Jinniu, Chengdu, Sichuan 610072, P.R. China

E-mail: jeannelxiang@cdutcm.edu.cn

*Contributed equally

Key words: glaucoma, retinal ganglion cells, apoptosis, hydrostatic pressure, nerve growth factor significantly lower under 40,60 and $80 \mathrm{mmHg}$ compared with under 0 or $20 \mathrm{mmHg}$ (all $\mathrm{P}<0.01$ ). The expression and mRNA levels of NGF, AKT and CREB decreased in a dose-dependent manner in the 40-, 60- and $80-\mathrm{mmHg}$ groups (all $\mathrm{P}<0.05$ ), but those of ASK1 and FoxO1 increased in a dose-dependent manner (all $\mathrm{P}<0.05$ ). Interestingly, the alterations to the expression and mRNA levels of CREB were significantly larger compared with the changes in ASK1 or FoxO1 in the $40-, 60-$ and $80-\mathrm{mmHg}$ groups (all $\mathrm{P}<0.01$ ). The results of the present study demonstrate that elevated HP of 40,60 or $80 \mathrm{mmHg}$ reduces viability and induces apoptosis in RGCs, which may occur through effects on the NGF/ASK1/FoxO1 and NGF/AKT/CREB pathways, of which the latter is more strongly affected.

\section{Introduction}

Glaucoma, affecting $~ 80$ million people, is the leading cause of irreversible blindness globally (1). Retinal ganglion cell (RGC) degeneration and a progressive loss of visual fields are the primary features of glaucoma (2). Normal pressure is one of the essential conditions for cellular function and cell integrity; high intraocular pressure (HIOP) is considered to be the main risk factor enhancing RGC death and visual functional damage in glaucoma (3). However, the underlying molecular mechanisms of consistent RGC loss induced by HIOP remain unclear (4). Further insight into the pathogenesis of glaucoma is critical for protecting RGCs.

Nerve growth factor (NGF) may protect RGCs against apoptosis induced by palmitic acid injury, and the effect is partly modulated by protein kinase B (AKT)/forkhead box O1 (FoxO1) (5). AKT /Activation of cAMP-responsive element binding protein 1 (CREB1) activity may play an important role to control the viability of neuronal cells during retinal development (6). FoxO1 serves a crucial function in modulating apoptosis and survival in multiple cell types (7-9). Cyclin-dependent kinase-5 can modulate of the cellular location of FoxO1 for regulating the apoptosis of neurons (10). 
In addition, deletion of the apoptosis signal-regulating kinase 1 (ASK1) gene may also prevent RGC death in mouse models of glaucoma (11). CREB may also protect RGCs against death following axotomy (12). Although the above studies have suggested that NGF, AKT, ASK1, FoxO1 and CREB have crucial functions in RGC apoptosis in palmitic acid injury models or RGC death in mouse models, there is no direct evidence to demonstrate whether they function in RGCs with in vitro hydrostatic pressure (HP)-induced damage.

In the present study, the degree to which HP caused apoptosis in RGCs cultured for $24 \mathrm{~h}$ was initially determined, and subsequently the underlying mechanisms of accelerated RGC apoptosis were investigated by measuring the protein and mRNA expression levels of NGF, AKT, ASK1, FoxO1 and CREB, paving the way for the discovery of novel therapeutic strategies to protect RGCs and preserve vision in patients with glaucoma.

\section{Materials and methods}

Cell separation and primary culture. Retinas from new-born Sprague Dawley rats were dissociated by trituration and dissociated in $1.25 \mathrm{~g} / 1$ trypsin and $2 \mathrm{~g} / \mathrm{l}$ hyaluronidase (Thermo Fisher Scientific, Inc., Waltham, MA, USA). RGCs from retinas were purified by Thy-1.1 antibody panning as previously described (13). Cell suspensions were transferred to a petri dish coated with rat monoclonal anti-macrophage antibody (1:75; cat no. ab56297; Abcam, Cambridge, UK) for $45 \mathrm{~min}$ at room temperature, then loaded into a petri dish coated with horseradish peroxidase (HRP)-conjugated goat anti-rabbit immunoglobulin (Ig)G (1:400; cat no. ab97057; Abcam) for $30 \mathrm{~min}$ at room temperature to isolate microglia. Cells separated from the petri dish wall were transferred to another petri dish coated with HRP-conjugated goat anti-rabbit IgM (1:300; cat no. ab97180; Abcam) and mouse anti-rat monoclonal antibody Thy1.1 (1:100; cat no. ab6721; Abcam) for $30 \mathrm{~min}$ at room temperature, following which the cells that separated from the petri dish wall were removed. Next, trypsin digestion was performed at $37^{\circ} \mathrm{C}$ for $8 \mathrm{~min}$, following which the cells were pelleted by centrifugation at $500 \mathrm{x}$ g for $5 \mathrm{~min}$ at room temperature and seeded onto 96-well plates coated with poly-Aminutrin and laminin. Following incubation at $37^{\circ} \mathrm{C}$ for $24 \mathrm{~h}$, purified RGCs were grown in fresh cell culture medium (97.5\% Neurobasal Medium, 2\% B27 and $0.5 \%$ $200 \mathrm{mM} / 1 \mathrm{~L}$-glutamine) at $37^{\circ} \mathrm{C}$ in a $5 \% \mathrm{CO}_{2}$ atmosphere. The medium was then refreshed every two days. The growth status and morphological changes were observed using an inverted phase contrast optical microscope (CKX31/41; Olympus Corporation, Tokyo, Japan) at x100 magnification. The cells were then collected for further analysis. The present study was ethically approved by the Ethics Committee for Animal Research of Chengdu University of Traditional Chinese Medicine (Chengdu, China).

Pressure system. An open pressure control system was designed to stimulate the cultured RGCs with stable, adjustable elevated HP as previously described (14). The plexiglass pressure chamber was concatenated via a low-pressure two-stage regulator (cat no. A032009; Thermo Fisher Scientific, Inc.) to a source of $5 \% \mathrm{CO}_{2} / 95 \%$ oxygen air (Thermo Fisher
Scientific, Inc.). This system provided constant HP ranging from $0-200 \mathrm{mmHg}$. Gas to the chamber was warmed and humidified by bubbling through water. The water flask and pressure chamber were maintained at $37^{\circ} \mathrm{C}$ via placement in an electronically controlled conventional incubator. Notably, the system had the advantages of easy and precise control of the gas flow and pressure.

Experimental group. Purified RGCs were cultured for $48 \mathrm{~h}$, then subsequently divided into five groups, namely, the $0-, 20-, 40-, 60-$ and 80-mmHg groups. RGCs in the 0-, 20-, $40-, 60-$ and $80-\mathrm{mmHg}$ groups were exposed to HPs of $0-, 20-$, $40-, 60-$ and $80-\mathrm{mmHg}$, respectively, for $24 \mathrm{~h}$.

Detecting viability with a Cell Counting Kit-8 (CCK-8). Following the application of different HPs for $24 \mathrm{~h}, \mathrm{RGC}$ viability was measured using a CCK-8 (Dojindo Molecular Technologies, Inc., Kumamoto, Japan) assay according to the manufacturer's protocol. In brief, $0.1 \mathrm{ml}$ cell suspension per well were seeded in a 96-well culture plate at a density of $5 \times 10^{4} \mathrm{RGCs} / \mathrm{ml}$. A total of $10 \mu \mathrm{l} \mathrm{CCK}-8$ solution was added to each well of the plate. Subsequent to a $4 \mathrm{~h}$ incubation at $5 \%$ $\mathrm{CO}_{2}$ and $37^{\circ} \mathrm{C}$, the optical density 450 of each well of the plate was measured with a Tecan Genios reader (Varioskan ${ }^{\mathrm{TM}}$ LUX, Thermo Fisher Scientific, Inc.). There were three replicates for each group.

Measuring apoptosis rate with Annexin $V$ fluorescein isothiocyanate (FITC)/propidium iodide (PI) flow cytometry. Subsequent to being subjected to different HPs for $24 \mathrm{~h}$, RGCs were collected following trypsinization using a pancreatic enzyme (Procell Life Science and Technology Co. Ltd., Wuhan, China) without ethylenediaminetetraacetic acid and centrifuged at $200 \mathrm{x} \mathrm{g}$ for $5 \mathrm{~min}$ at room temperature. The collected cells were re-suspended in pre-cooled 1x phosphate buffered saline (PBS) at $200 \mathrm{x} \mathrm{g}$ for 5-10 min, then washed twice and suspended in 1x Binding Buffer of $300 \mu \mathrm{l}$. A total of $5 \mu$ l FITC-conjugated Annexin V (Nanjing KeyGen Biotech Co., Ltd., Nanjing, China) was added to the cell suspension. The cells were then incubated for $15 \mathrm{~min}$ at room temperature in the dark, then washed with binding buffer and analysed by flow cytometry using Cell Quest software (version 7.5.3; BD Biosciences, Franklin Lakes, NJ, USA). Experiments were performed at least 3 times.

Western blotting. Total protein (25 $\mu \mathrm{g}$ per sample) was extracted from the retinal tissues and the protein concentration was determined by BCA assay kit (Pierce Biotechnology; Thermo Fisher Scientific, Inc.). The proteins were subjected to $8-13 \%$ SDS-PAGE gel electrophoresis and transferred onto a polyvinylidene fluoride membrane, the membrane was immersed in 5\% skim milk and incubated for $12 \mathrm{~h}$ at $4^{\circ} \mathrm{C}$ with primary antibodies, including mouse monoclonal anti- $\beta$-actin (1:200; cat no. ab6199; Abcam), rabbit anti-rat NGF polyclonal antibody (1:200; cat no. ab6199; Abcam), rabbit anti-rat AKT polyclonal antibody (1:200; cat no. ab8805; Abcam), rabbit anti-rat ASK1 polyclonal antibody (1:200 cat no. ab131506; Abcam), rabbit anti-rat FoxO1 polyclonal antibody (1:200; cat no. ab12161; Abcam) and rabbit anti-rat CREB polyclonal antibody (1:200; cat no. ab31387; Abcam). The proteins 
Table I. Primers used for NGF, AKT, ASK1, FoxO1, CREB and $\beta$-actin.

\begin{tabular}{llll}
\hline mRNA & Genbank ID & Primer & Sequence (5'-3') \\
\hline NGF & XM_006233053.2 & Forward & Reverse \\
AKT & NM_033230.2 & Forward & $\begin{array}{l}\text { CATAGCGTAATGTCCATGTTGTTCT } \\
\text { CAGTATGTTGCGGGTCTGC } \\
\text { CCTGAAGCTACTGGGCAAGGG }\end{array}$ \\
ASK1 & NM_001277694.1 & Reverse & ACAAAGCAGAGGCGGTCGTG \\
& & Forward & GGGCCGATCTGCTTACCTCT \\
FoxO1 & NM_001191846.2 & Reverse & TCAGCCGCCAACTCTTTACC \\
CREB & Forward & TCCTCGAACCAGCTCAAACGC \\
& & Reverse & GGATACACCAGGGAATGCACATC \\
-actin & Forward & TAGTGCCCAGCAACCAAGTT \\
& NM_031144.3 & Reverse & TGCTTCCCTGTTCTTCATTAGAC \\
& & Forward & ACCCGCGAGTACAACCTTCTT \\
\hline
\end{tabular}

NGF, nerve growth factor; AKT, protein kinase B; ASK1, apoptosis signal-regulating kinase 1; FoxO1, forkhead box O1; CREB, cAMP-response element binding protein.

were then incubated with HRP-conjugated goat-anti-rabbit IgG secondary antibodies (1:500; cat no. ab97057; Abcam) for $45 \mathrm{~min}$ at $37^{\circ} \mathrm{C}$. Following a final wash in tris-buffered saline with $0.1 \%$ Tween-20, the membrane was reacted with electrochemiluminescence reagent (Merck KGaA, Darmstadt, Germany). Densitometric analysis was performed by ImageJ software (1.48 u; National Institutes of Health, Bethesda, MD, USA) and normalized to $\beta$-actin.

Immunofluorescence staining. Cells on coverslips were fixed with $4 \%$ paraformaldehyde for $20 \mathrm{~min}$ at room temperature. Next, the coverslips were washed with PBS (pH 7.4) for $3 \mathrm{~min}$ and incubated in 5\% bovine serum albumin (Sigma-Aldrich; Merck $\mathrm{KGaA}$ ) at room temperature for $1 \mathrm{~h}$. Immunoreaction was then performed overnight with monoclonal anti-mouse Thy1.1 antibody (1:100; cat no. ab6721; Abcam). All coverslips were subsequently treated with anti-mouse immunoglobulin G H\&L secondary antibodies (1:200; cat no. ab6720; Abcam) for $60 \mathrm{~min}$ at $37^{\circ} \mathrm{C}$. The cell nuclei were counterstained with DAPI for $10 \mathrm{~min}$ at room temperature, then covered with an anti-fading mounting medium prior to optical microscopy (CKX31/41; Olympus Corporation) at x100 and x200 magnification. Fluorescent intensities were quantified using Image-Pro ${ }^{\circledR}$ Plus 6.0 software (Media Cybernetics, Inc., Rockville, MD, USA).

Reverse transcription-quantitative polymerase chain reaction $(R T-q P C R)$. Total RNA was extracted using TRIzol reagent (Invitrogen; Thermo Fisher Scientific, Inc.) according to the manufacturer's protocol. A reverse transcriptase cDNA synthesis kit (Toyobo Life Science, Osaka, Japan) was used for obtaining cDNA. qPCR was performed using the SYBR Green PCR Master Mix (Applied Biosystems; Thermo Fisher Scientific, Inc.) with the Applied Biosystems 7500 RT-PCR system (Applied Biosystems; Thermo Fisher Scientific, Inc.). The RT-qPCR thermocycling conditions were as follows: A total of 2 min initial denaturation at $95^{\circ} \mathrm{C}$, then 45 cycles of denaturation at $95^{\circ} \mathrm{C}$ for $10 \mathrm{sec}$ and annealing at $60^{\circ} \mathrm{C}$ for $30 \mathrm{sec}$. The relative expression levels of the target mRNAs were normalized to that of $\beta$-actin. The $2^{-\Delta \Delta \mathrm{Cq}}$ method (15) was used to calculate the relative fold changes in mRNA expression. The sequences of the primer pairs are presented in Table I.

Statistical analysis. All data are presented as the mean \pm standard deviation. Statistical analysis was performed in SPSS 21.0 (IBM Corp., Armonk, NY, USA). Comparisons were performed using one-way analysis of variance, and the comparison between specific groups was performed using the least significant difference test. $\mathrm{P}<0.05$ was considered to indicate a statistically significant difference.

\section{Results}

Identification and purity testing of RGCs. Immunofluorescence was used to identify RGCs and detect their purity with an anti-Thy1.1 antibody. Areas of positive fluorescent green signal observed by fluorescent microscopy mainly appeared in the cytomembrane. Certain cell neurites also exhibited green fluorescence. RGC purity was calculated as the proportion of the number of cells marked with green fluorescence out of the total number of cells in a given field of view by inverted phase contrast microscopy. The results from 12 fields of view demonstrated that the purity of the RGCs was $96.97 \%$ (Fig. 1).

Elevated HP induces apoptosis-associated morphological changes in RGCs in vitro. Ohashi et al (16) reported that elevated HP influences the morphological changes of cells. In the present study, morphological changes in RGCs were observed by inverted phase contrast microscopy. In the $0-\mathrm{mmHg}$ group, the cells tended to congregate and present long neurites (Fig. 2A). In the $20-\mathrm{mmHg}$ group, the RGCs were similar to those in the $0-\mathrm{mmHg}$ group (Fig. 2B). 


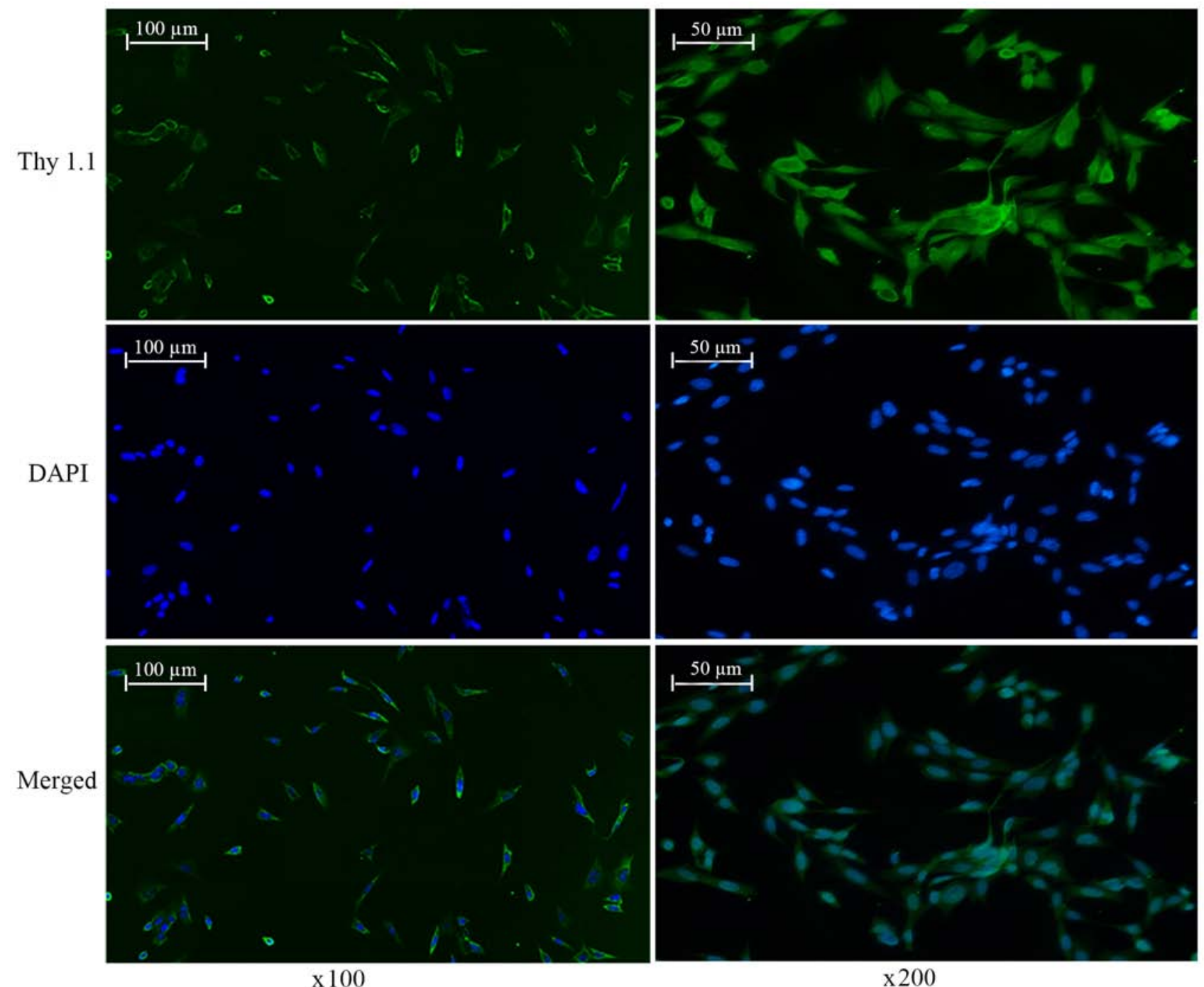

Figure 1. Identification and purity testing of retinal ganglion cells. Green is Thy1.1 immunofluorescence staining and blue is DAPI staining (magnification, $\mathrm{x} 100$ and $\mathrm{x} 200)$.

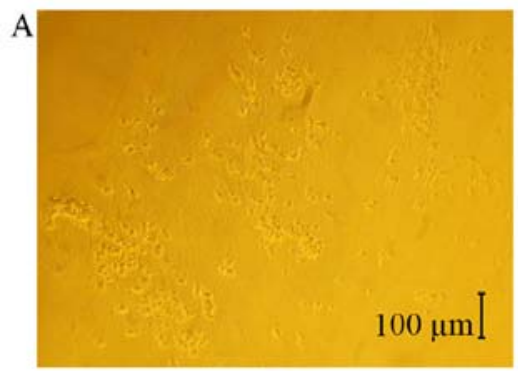

D

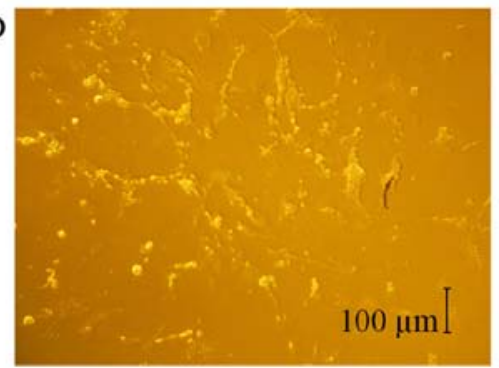

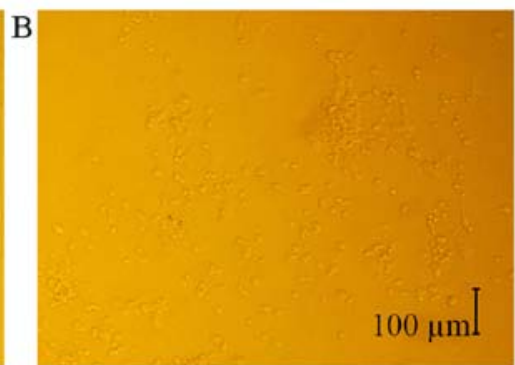
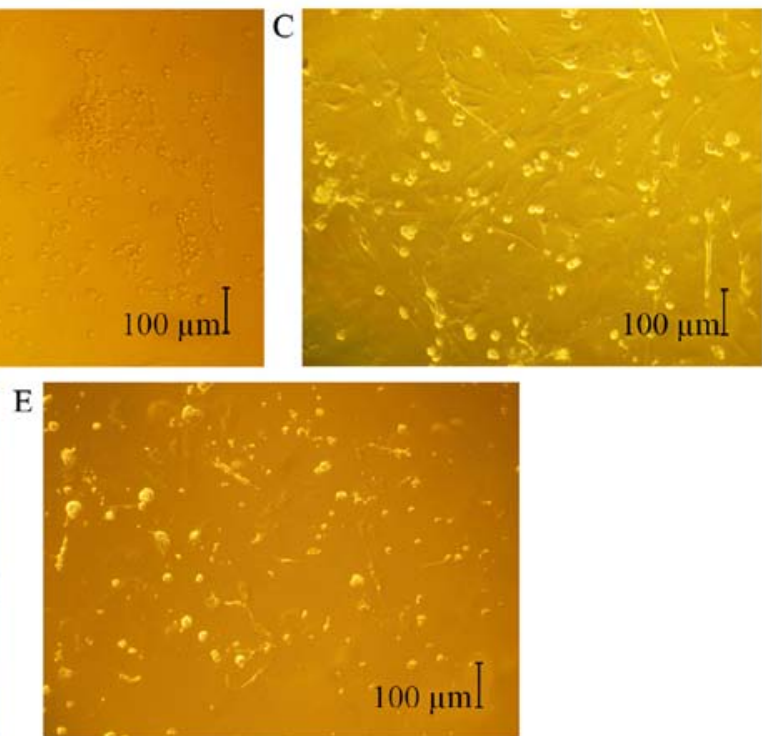

Figure 2. Elevated HP induced apoptotic morphological changes in RGCs in vitro. The effect was observed by inverted phase contrast microscopy. (A) Micrograph of RGCs cultured at HP values of $0 \mathrm{mmHg}$ (magnification, x100). (B) Micrograph of RGCs cultured at $\mathrm{HP}$ values of $20 \mathrm{mmHg}$ (magnification, x100). (C) Micrograph of RGCs cultured at $\mathrm{HP}$ values of $40 \mathrm{mmHg}$ (magnification, x100). (D) Micrograph of RGCs cultured at $\mathrm{HP}$ values of $60 \mathrm{mmHg}$ (magnification, x100). (E) Micrograph of RGCs cultured at HP values of $80 \mathrm{mmHg}$ (magnification, x100). HP, hydrostatic pressure; RGC, retinal ganglion cell. 

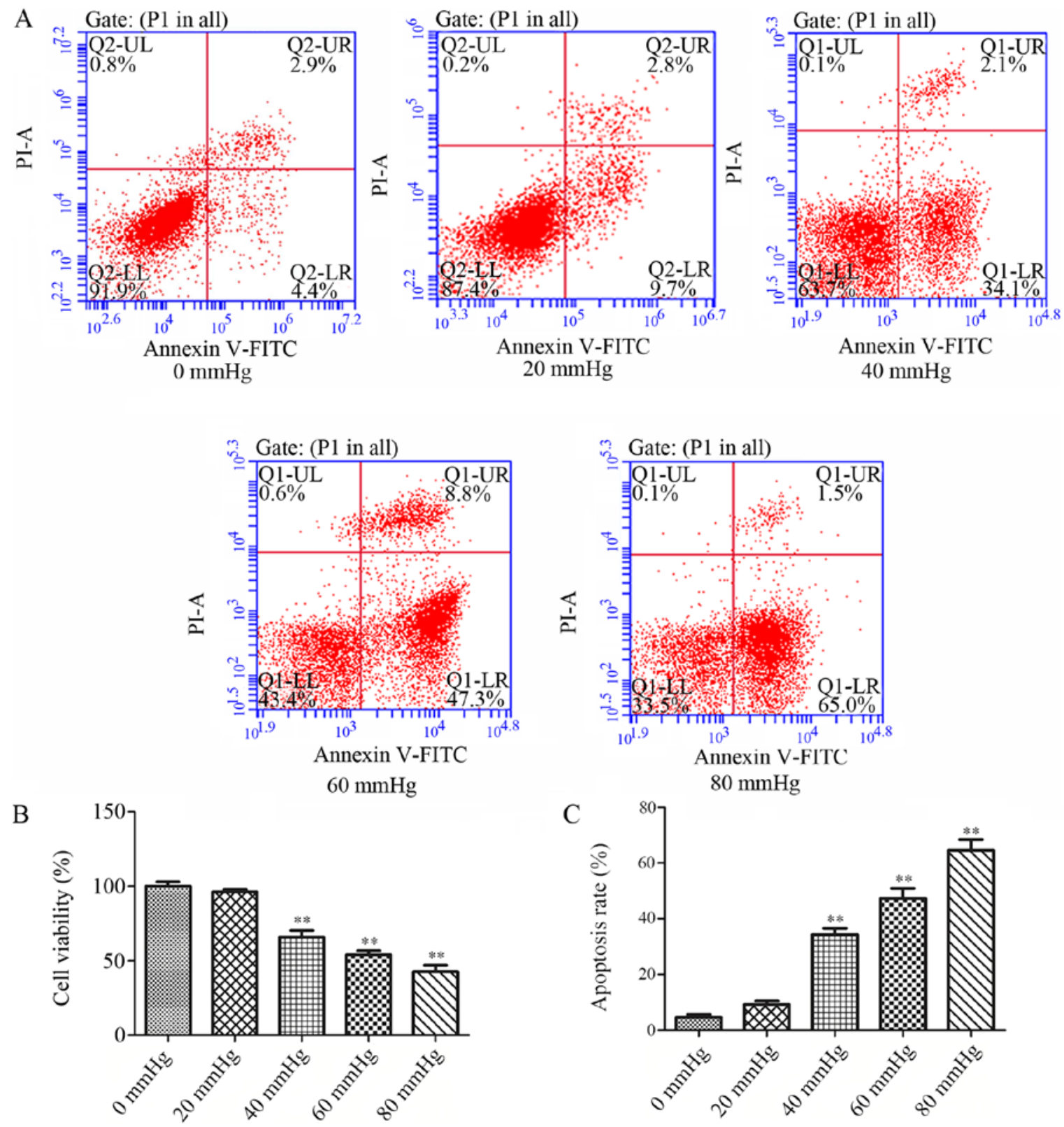

Figure 3. Elevated HP reduced viability and induced apoptosis in RGCs in vitro. These effects were observed using a Cell Counting K-8 assay and by Annexin V FITC/PI flow cytometry, respectively. (A) Annexin V FITC/PI flow cytometry results at different $\mathrm{HP}$ values $(0,20,40,60 \mathrm{and} 80 \mathrm{mmHg})$. (B) Quantification of cell viability rates. (C) Quantification of cell apoptosis rates. Data are presented as the mean \pm standard deviation $(\mathrm{n}=3)$. ${ }^{* *} \mathrm{P}<0.01 \mathrm{vs}$. the $0 \mathrm{mmHg}$ group. HP, hydrostatic pressure; RGC, retinal ganglion cell; PI, propidium iodide; FITC, fluorescein isothiocyanate; UL, upper left; UR, upper right; LL, lower left; LR, lower right.

However, in the 40-mmHg group, sections of the cell bodies were shrunken, and certain cell membranes were disrupted, although a number of cells remained intact (Fig. 2C). In the $60-\mathrm{mmHg}$ group, there were numerous floating cells with shrunken cell bodies and incomplete cell membranes. In addition, the extension of the neurites was weakened, parts of the cells were disintegrating or dying and the internal structures of the cells were only dimly visible (Fig. 2D). In the $80-\mathrm{mmHg}$ group, the apoptotic morphological changes in the RGCs were similar compared with those of the $60-\mathrm{mmHg}$ group, but the internal structures of the cells were not visible at all (Fig. 2E). These results indicate that HPs of 40,60 and $80 \mathrm{mmHg}$ may induce apoptotic morphological changes in RGCs in vitro.
Elevated HP reduces viability and induces apoptosis in RGCs in vitro. Once cells were subjected to different HPs for $24 \mathrm{~h}$, Annexin V FITC/PI flow cytometry results revealed that the apoptosis rates of the 40-, 60- and $80-\mathrm{mmHg}$ groups were significantly higher $(\mathrm{P}<0.01$; Fig. $3 \mathrm{~A}$ and $\mathrm{C})$ and the viability rates were significantly lower $(\mathrm{P}<0.01$; Fig. $3 \mathrm{~B})$ compared with those of the 0 -mmHg group. These results are consistent with those of Li et al (17) and Zhang et al (18), whose studies demonstrated that elevated HP may cause apoptosis in RGCs in vitro. In the present study, the apoptosis rates gradually increased and the viability rates gradually decreased from the $40 \mathrm{mmHg}$ to the $80 \mathrm{mmHg}$ group $(\mathrm{P}<0.05$; Fig. $3 \mathrm{~B}$ and $\mathrm{C})$. However, there was no significant difference in apoptosis rates or viability rates between the $0-\mathrm{mmHg}$ group and $20-\mathrm{mmHg}$ groups $(\mathrm{P}>0.05$; 


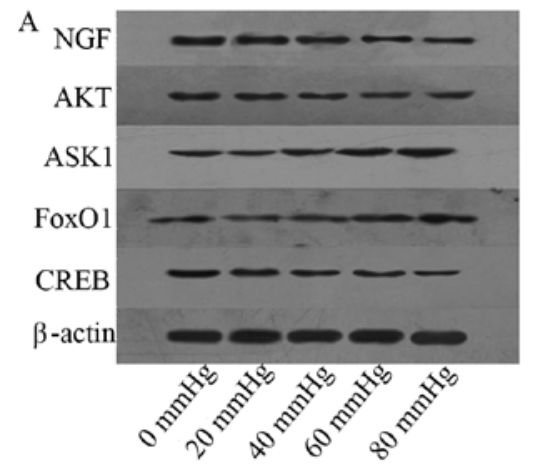

$\mathrm{D}$

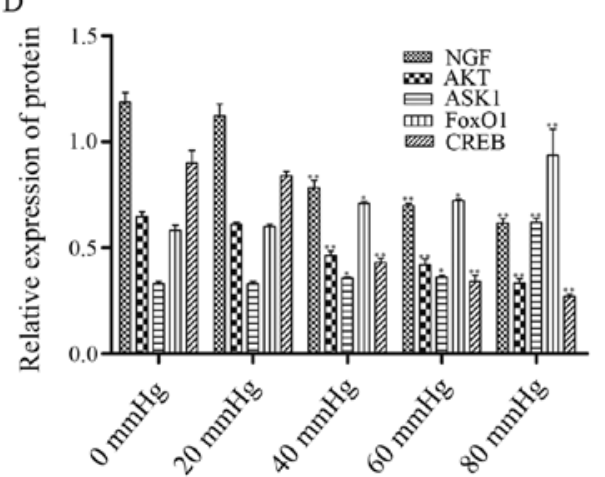

B

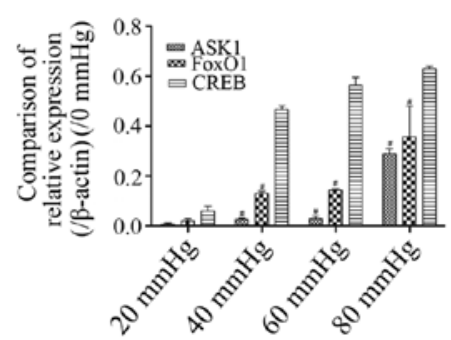

$\mathrm{C}$

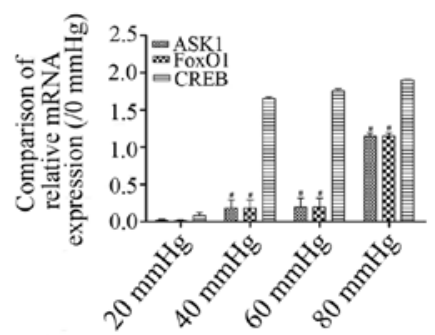

E

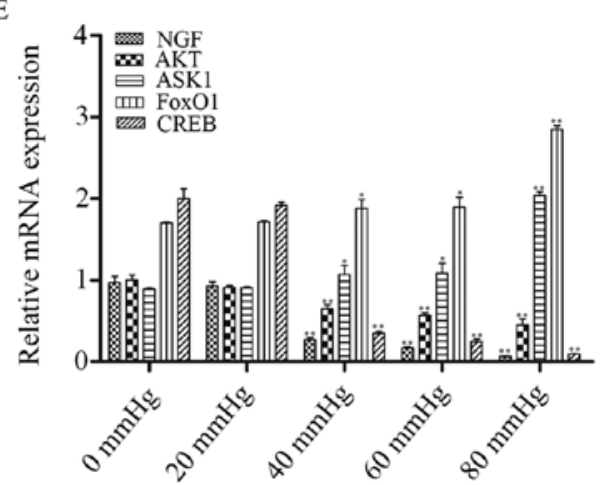

Figure 4. Influence of elevated HP on mRNA and protein expression levels in pressure-treated RGCs. (A) NGF, AKT, ASK1, FoxO1 and CREB protein expression levels of RGCs were detected by western blotting. (B) Quantified protein expression of ASK1, FoxO1 and CREB at 20, 40,60 and 80 mmHg compared with $0 \mathrm{mmHg}$. (C) Quantified mRNA expression levels of ASK1, FoxO1 and CREB at 20, 40, 60 and $80 \mathrm{mmHg}$ compared with $0 \mathrm{mmHg}$. To compare the NGF/ASK1/FoxO1 and NGF/AKT/CREB pathways, the expression levels at $0 \mathrm{mmHg}$ were defined as the baseline; the data were calculated by subtracting the protein and mRNA expression levels at $0 \mathrm{mmHg}$ from the protein and mRNA expression levels at 20,40,60 and $80 \mathrm{mmHg}$. (D) Quantified protein expression levels of NGF, AKT, ASK1, FoxO1 and CREB. (E) Quantified mRNA expression levels of NGF, AKT, ASK1, FoxO1 and CREB. Data are presented as the mean \pm standard deviation $(\mathrm{n}=3)$. ${ }^{~} \mathrm{P}<0.01$ vs. CREB at the same level of HP. ${ }^{*} \mathrm{P}<0.05$ and ${ }^{* * *} \mathrm{P}<0.01$ vs. the $0 \mathrm{mmHg}$ group. HP, hydrostatic pressure; RGC, retinal ganglion cell; NGF, nerve growth factor; AKT, protein kinase B; ASK1, apoptosis signal-regulating kinase 1; FoxO1, forkhead box O1; CREB, cAMP response element binding protein.

Fig. 3B and C). These results indicate that elevated HP of 40, 60 , or $80 \mathrm{mmHg}$ notably reduces the viability rate and increases the apoptosis rate of RGCs cultured for $24 \mathrm{~h}$.

Elevated HP promotes RGC apoptosis by altering the expression of NGF, AKT, ASK1, FoxOl and CREB. Protein expression levels were analysed by western blotting and immunofluorescence, and mRNA expression levels were assessed using RT-qPCR (Figs. 4-9). Compared with the $0-\mathrm{mmHg}$ group, the protein and mRNA levels of NGF, AKT and CREB in the 40-, 60- and $80-\mathrm{mmHg}$ groups significantly decreased in a dose-dependent manner $(\mathrm{P}<0.05$; Fig. 4A, D and $\mathrm{E})$, while those of ASK1 and FoxO1 significantly increased in a dose-dependent manner ( $\mathrm{P}<0.05$; Fig. 4A, D and E). Similar results were confirmed by immunofluorescence $(\mathrm{P}<0.05$; Figs. 5-9). To evaluate the differences in the NGF/ASK1/FoxO1 and NGF/AKT/CREB pathways, the expression levels in the $0-\mathrm{mmHg}$ group were defined as the baseline; the data in Fig. 4B and $\mathrm{C}$ were calculated by subtracting the protein and mRNA expression levels at $0 \mathrm{mmHg}$ from the protein and mRNA expression levels at 20, 40, 60 and $80 \mathrm{mmHg}$. Interestingly, the changes in the protein and mRNA levels of CREB were significantly greater compared those of ASK1 or FoxO1 from an $\mathrm{HP}$ of 40 to $80 \mathrm{mmHg}(\mathrm{P}<0.01$; Fig. $4 \mathrm{~B}$ and $\mathrm{C})$. These results reveal that HPs of 40,60 and $80 \mathrm{mmHg}$ may restrain the expression of NGF, AKT and CREB and enhance the expression of ASK1 and FoxO1 to induce apoptosis in
RGCs in vitro. In addition, the expression of CREB changes more substantially compared with that of ASK1 or FoxO1.

\section{Discussion}

It is generally recognized that HIOP is a chief risk factor for expedited RGC apoptosis in glaucoma (19). A growing number of studies have demonstrated that increased apoptosis, proliferation and migration exist in cells treated with elevated HP $(20,21)$. Thus, cells exposed to elevated HP may generally function as an in vitro model of glaucomatous RGC apoptosis, as performed in the present study (22). Although Osborne et al (23) revealed that elevation of HP did not cause apoptosis in human RGCs cultured at $60 \mathrm{mmHg}$ for $24 \mathrm{~h}$, this difference may be associated with the speed of pressure fluctuations (24). In the present study, an open pressure control system was successfully established. In this system, HP values were first set as required. Next, five pressure values $(0,20,40,60$ and $80 \mathrm{mmHg})$ were selected to simulate HIOP injury. Finally, the present study was able to identify HP levels that resulted in the apoptosis of cultured RGCs. It was observed that treatment with 40,60 and $80 \mathrm{mmHg}$ over a period of $24 \mathrm{~h}$ reduced the viability rates and increased the apoptosis rates of RGCs. However, these patterns were not observed in the 0 - or $20-\mathrm{mmHg}$ group. Thus, the data suggests that a HP of 40,60 or $80 \mathrm{mmHg}$ may reduce viability and enhance apoptosis in RGCs in vitro, while $20 \mathrm{mmHg} \mathrm{HP}$ 
A
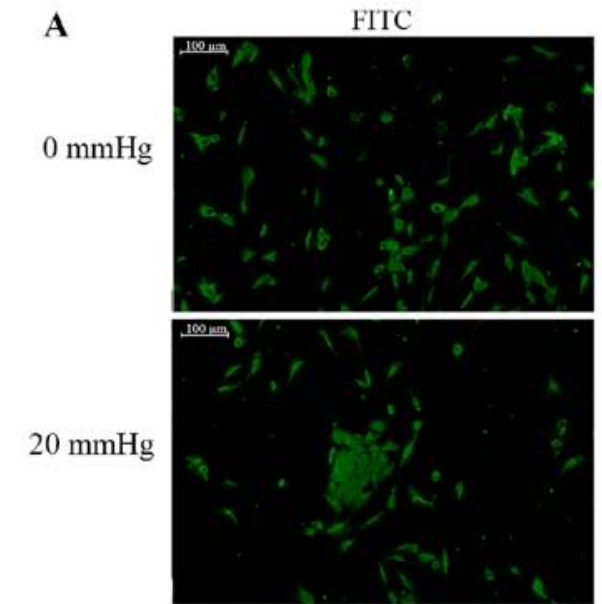

$40 \mathrm{mmHg}$

$60 \mathrm{mmHg}$

$80 \mathrm{mmHg}$
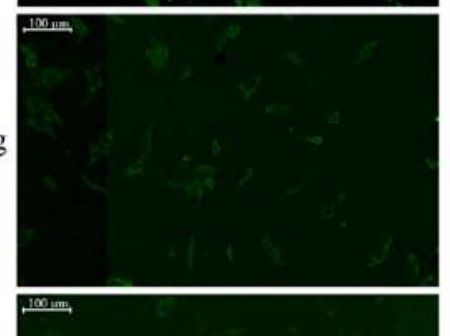

$$
\text { 西 }
$$
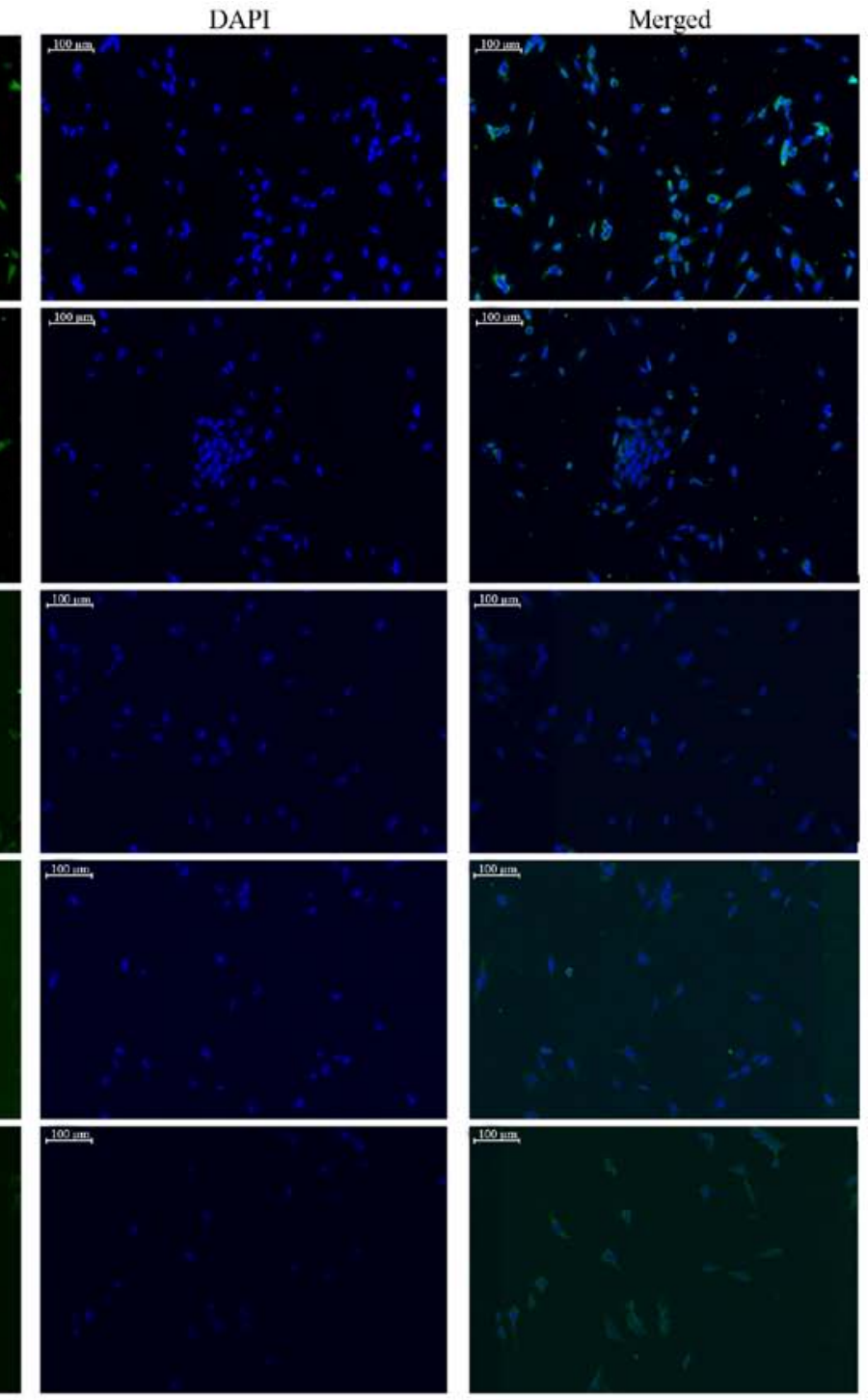

B

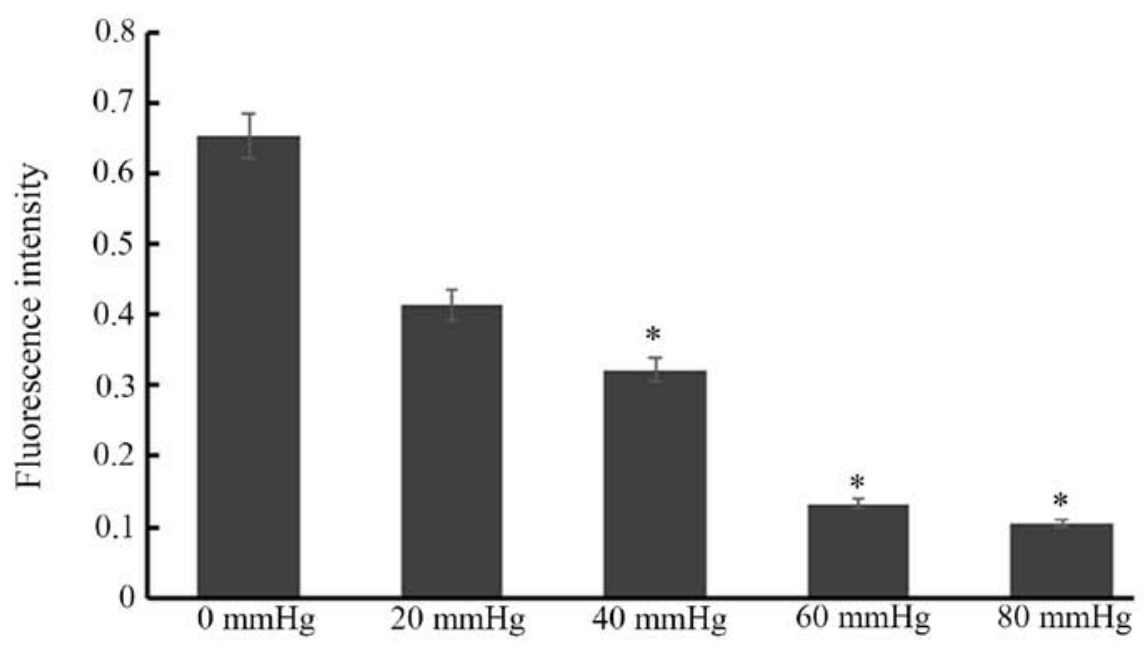

Figure 5. Influence of elevated HP on NGF protein expression in each group of RGCs. (A) Micrographs of immunofluorescence exhibiting NGF expression in RGCs. Green is FITC immunofluorescence staining, and blue is DAPI staining (magnification, x100). (B) Quantification and statistical analysis of fluorescence intensity. Data are presented as the mean \pm standard deviation $(\mathrm{n}=3)$. ${ }^{*} \mathrm{P}<0.05$ vs. the $0 \mathrm{mmHg}$ group. HP, hydrostatic pressure; RGC, retinal ganglion cell; NGF, nerve growth factor; FITC, fluorescein isothiocyanate.

does not cause RGC apoptosis, meaning that the viability and apoptosis rates of RGCs will not noticeably change until pressure reaches $40 \mathrm{mmHg}$.
Lee et al (25) reported that when RGC were exposed to pressure of $100 \mathrm{mmHg}$ for $20 \mathrm{~h}, 20$ out of 31 examined cells exhibited apoptotic morphological changes, presenting cell 
A

$0 \mathrm{mmHg}$

$20 \mathrm{mmHg}$

$40 \mathrm{mmHg}$
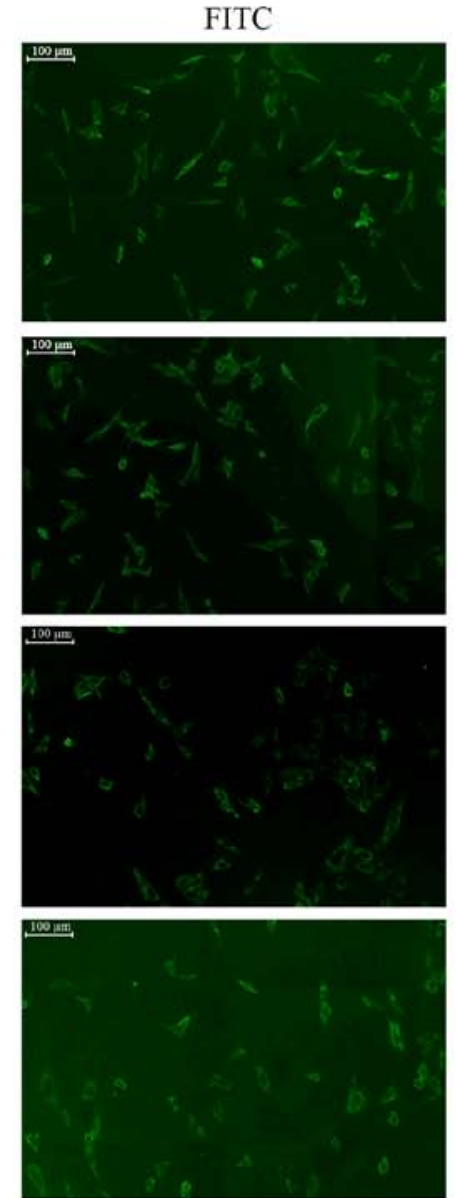

$60 \mathrm{mmHg}$

$80 \mathrm{mmHg}$

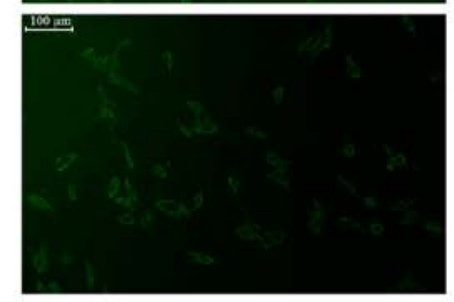

DAPI
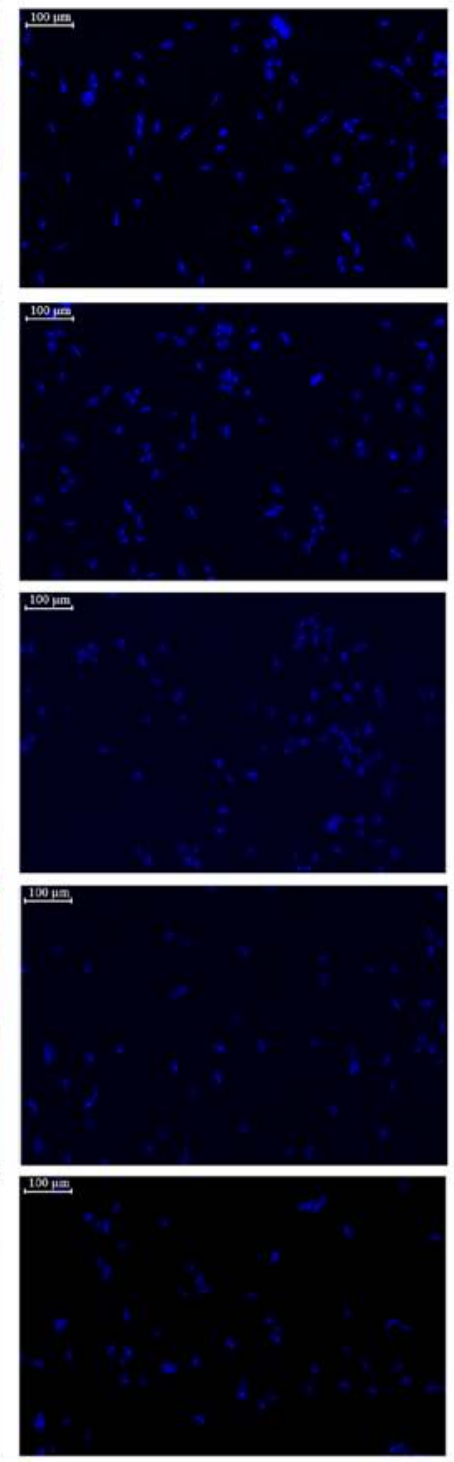

Merged
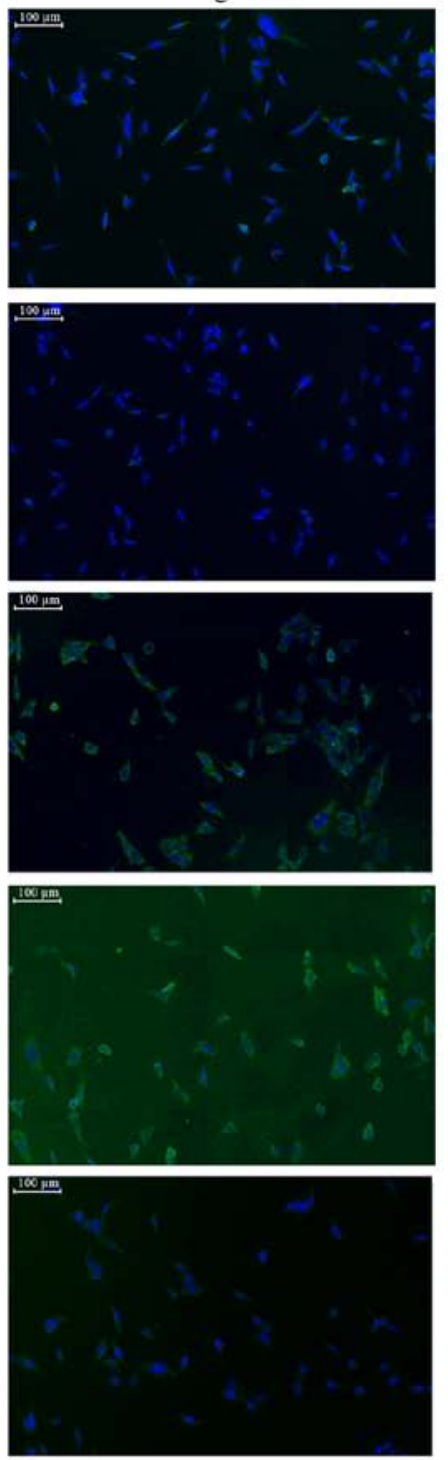

B

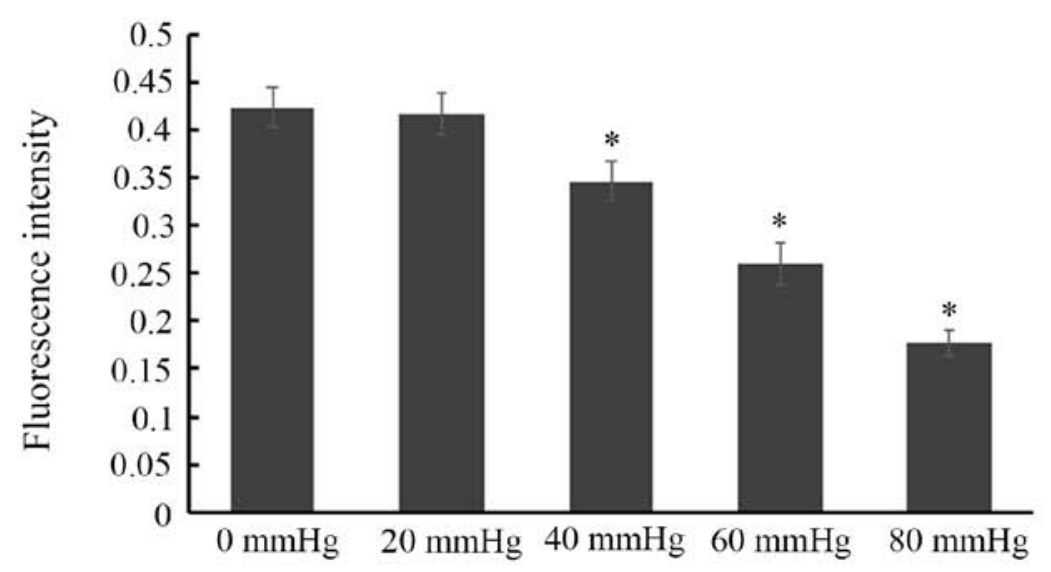

Figure 6. Influence of elevated HP on AKT protein expression in each group of RGCs. (A) Micrographs of immunofluorescence exhibiting AKT expression in RGCs. Green is FITC immunofluorescence staining, and blue is DAPI staining (magnification, x100). (B) Quantification and statistical analysis of fluorescence intensity. Data are presented as the mean \pm standard deviation $(n=3)$. ${ }^{*} \mathrm{P}<0.05$ vs. the $0 \mathrm{mmHg}$ group. HP, hydrostatic pressure; RGC, retinal ganglion cell; AKT, protein kinase B; FITC, fluorescein isothiocyanate.

body shrinkage and neurite retraction. However, only 3 out of 20 examined cells exhibited the spontaneous morphological changes of cell body shrinkage and neurite retraction under exposure to $15 \mathrm{mmHg}$ pressure (26). A report by Miao et al (20) had demonstrated that an elevated pressure of $60 \mathrm{mmHg}$ hindered cell migration. In the present study, an elevated HP 
A

FITC

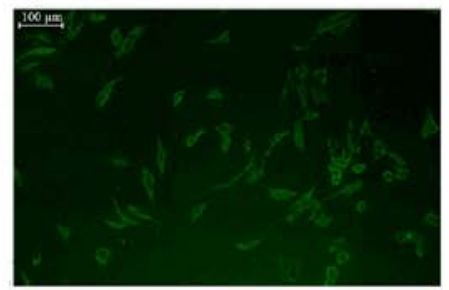

$20 \mathrm{mmHg}$

$40 \mathrm{mmHg}$
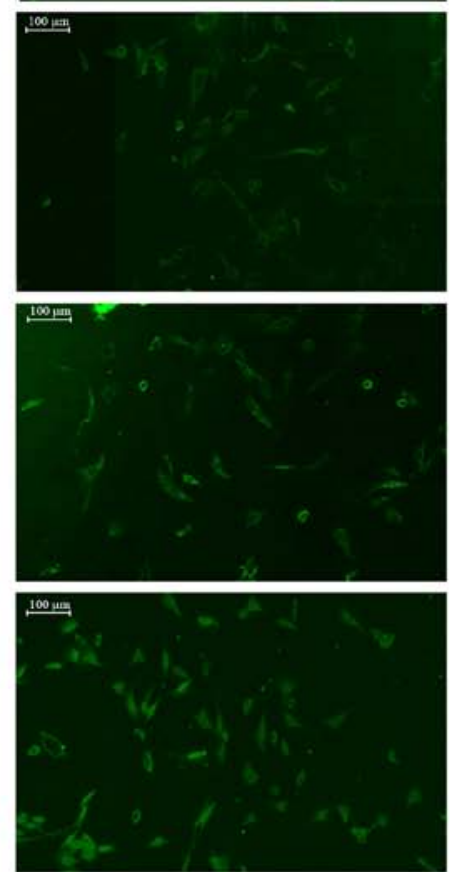

$60 \mathrm{mmHg}$

$80 \mathrm{mmHg}$

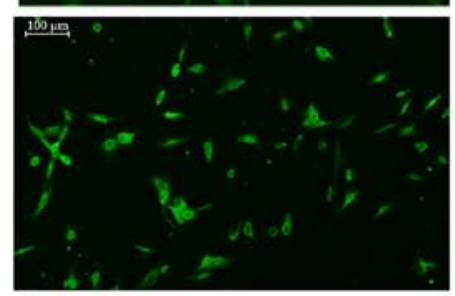

B

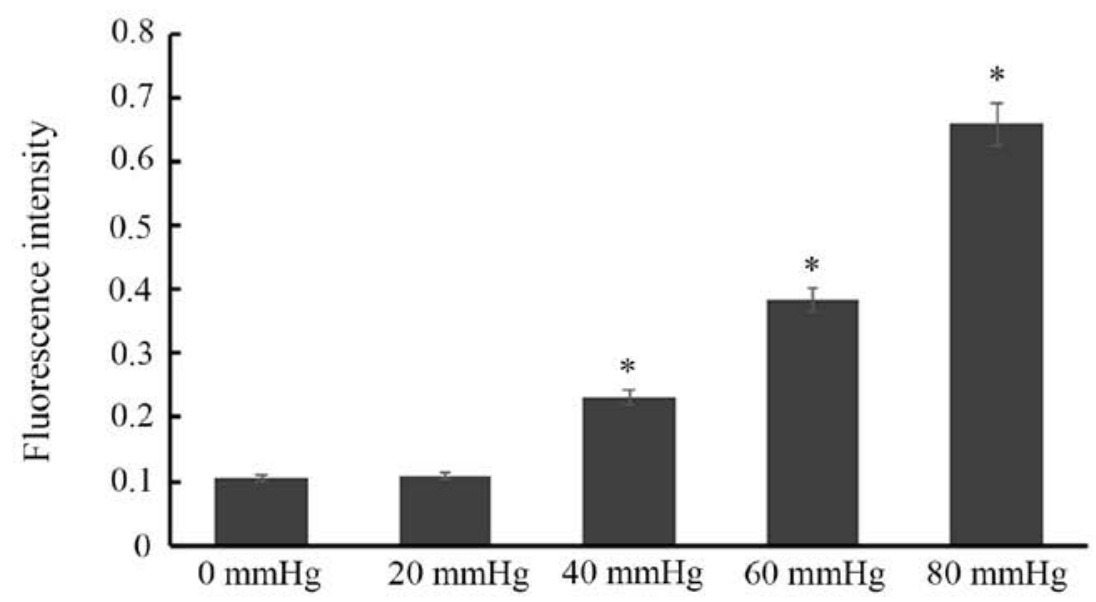

Figure 7. Influence of elevated HP on ASK1 protein expression in each group of RGCs. (A) Micrographs of immunofluorescence exhibiting ASK1 expression in RGCs. Green is FITC immunofluorescence staining, and blue is DAPI staining (magnification, x100). (B) Quantification and statistical analysis of fluorescence intensity. Data are presented as the mean \pm standard deviation $(n=3)$. ${ }^{*} \mathrm{P}<0.05$ vs. the $0 \mathrm{mmHg}$ group. HP, hydrostatic pressure; $\mathrm{RGC}$, retinal ganglion cell; ASK1, apoptosis signal-regulating kinase 1; FITC, fluorescein isothiocyanate. of 40, 60 and $80 \mathrm{mmHg}$ was revealed to induce apoptotic morphological changes including cell body shrinkage and neurite retraction of RGCs, in addition to the disintegration of
DAPI
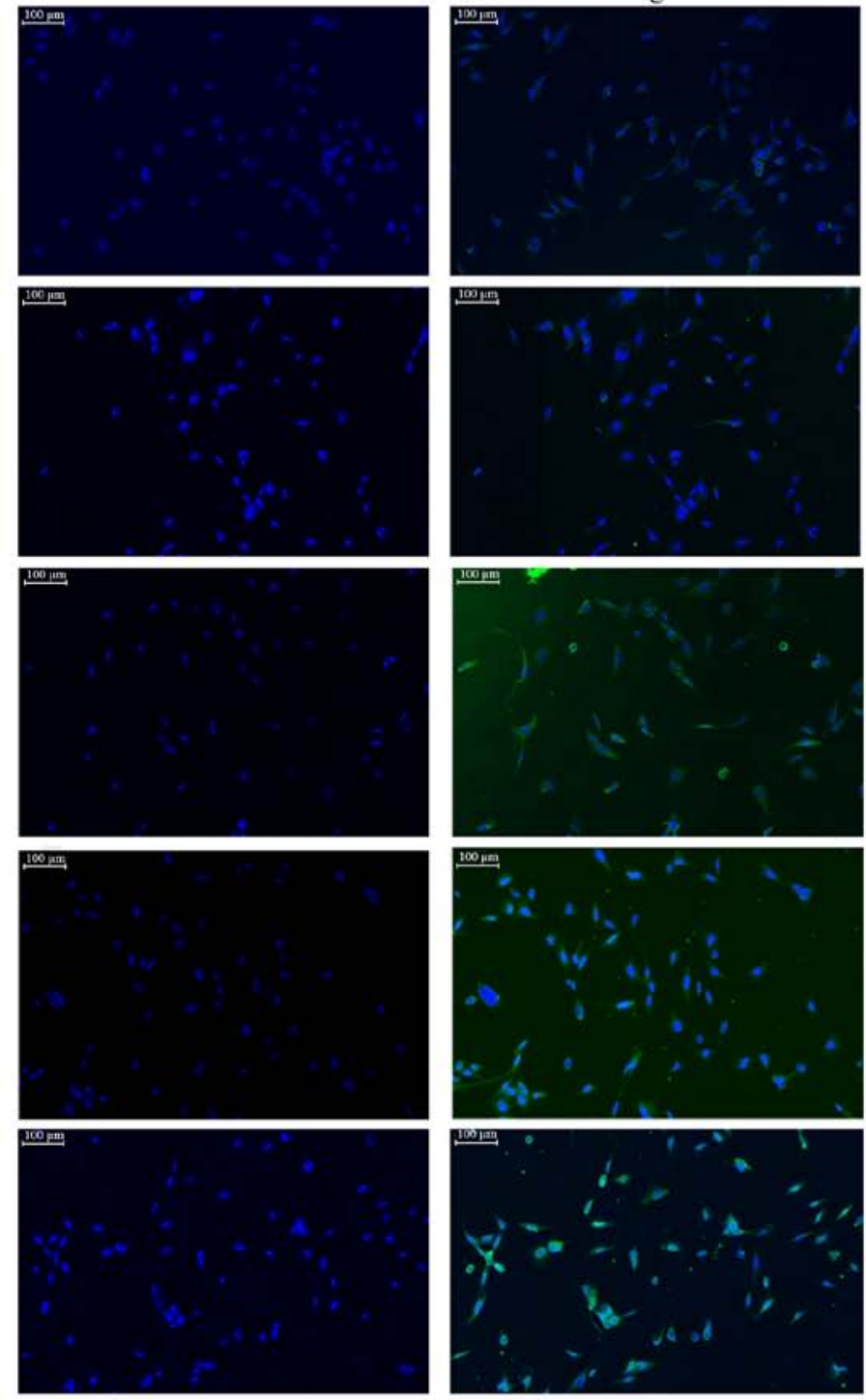

cells. These changes gradually increased with rising HP, which indicates that exposure to elevated HP may engender apoptotic morphological changes in RGCs. Lee et al (25) reported that 
A
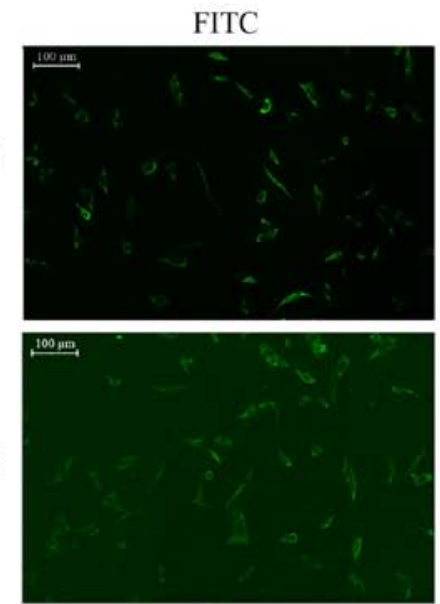

$20 \mathrm{mmHg}$

$40 \mathrm{mmHg}$

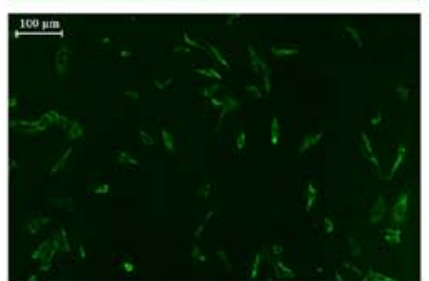

$60 \mathrm{mmHg}$
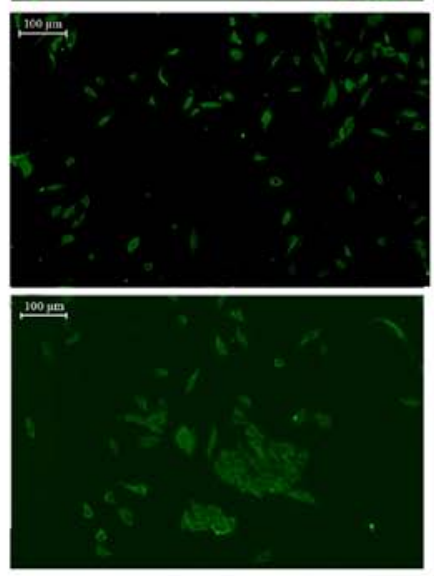

DAPI
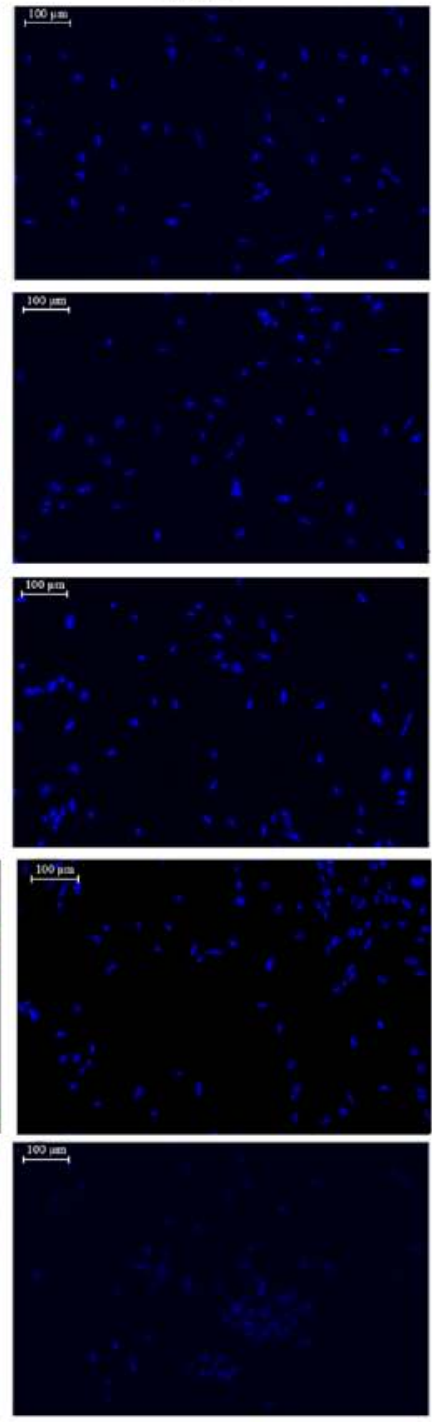
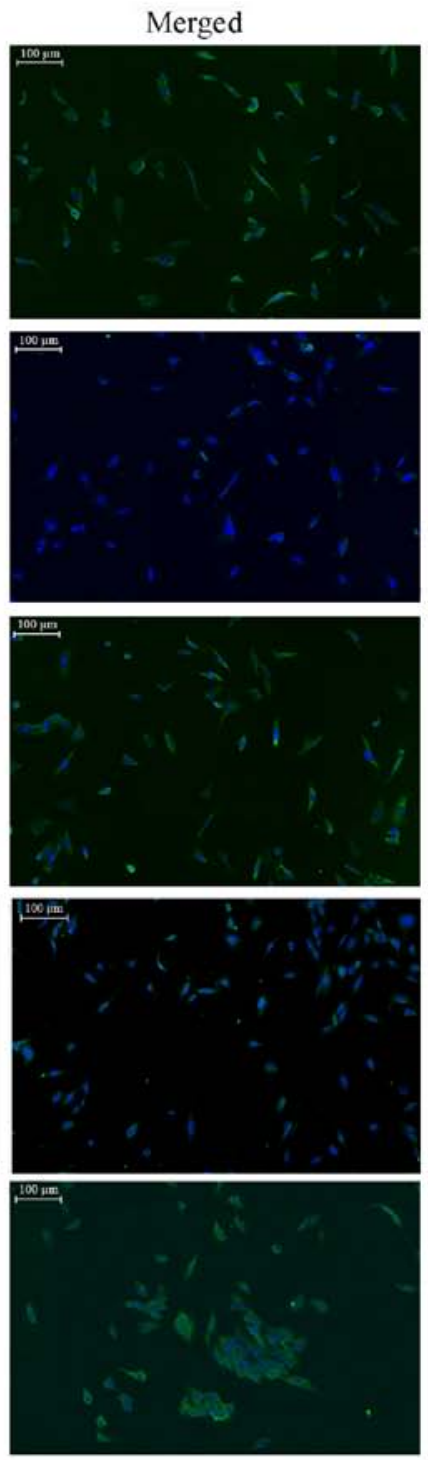

B

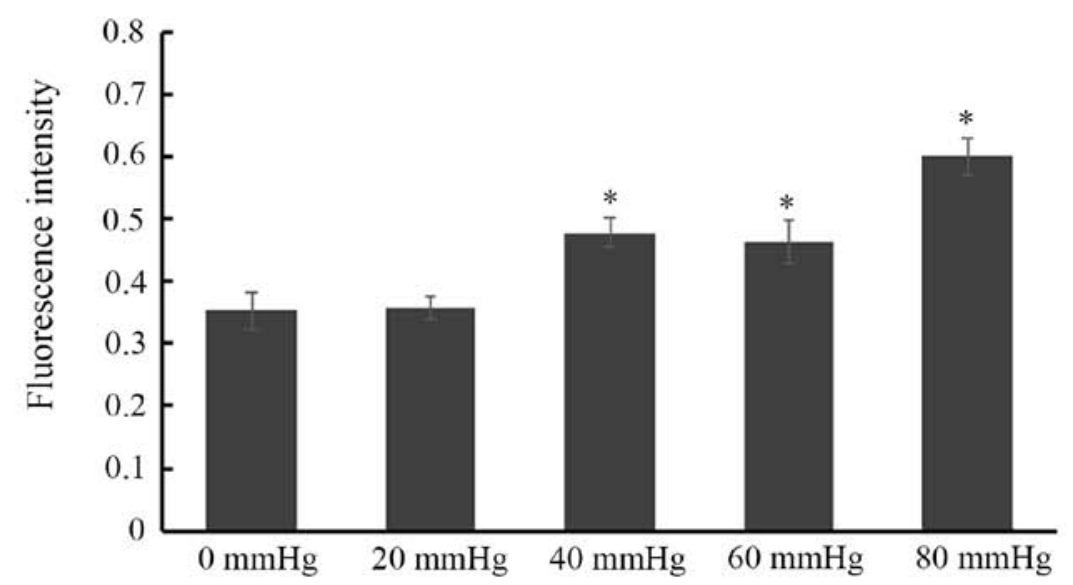

Figure 8. Influence of elevated HP on FoxO1 protein expression in each group of RGCs. (A) Micrographs of immunofluorescence exhibiting FoxO1 expression in RGCs. Green is FITC immunofluorescence staining, and blue DAPI staining (magnification, x100). (B) Quantification and statistical analysis of fluorescence intensity. Data are presented as the mean \pm standard deviation $(\mathrm{n}=3)$. " $\mathrm{P}<0.05$ vs. the $0 \mathrm{mmHg}$ group. HP, hydrostatic pressure; RGC, retinal ganglion cell; FoxO1, forkhead box O1; FITC, fluorescein isothiocyanate.

caspase- 3 activation was associated with the dismantling of the cytoskeleton and apoptotic morphological changes in RGCs exposed to high pressure. Cell apoptosis occurs by reduced activity of the NGF signalling pathway in connection with active caspase-3 (27). In the present study, there was reason to hypothesise that the underlying mechanisms of apoptotic 
A

FITC

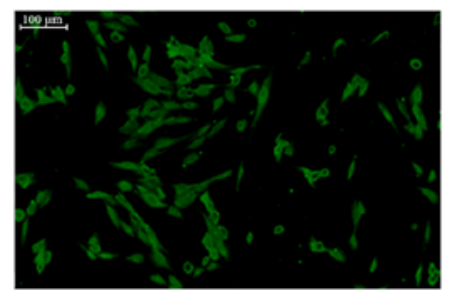

$20 \mathrm{mmHg}$

$40 \mathrm{mmHg}$

$60 \mathrm{mmHg}$

$80 \mathrm{mmHg}$
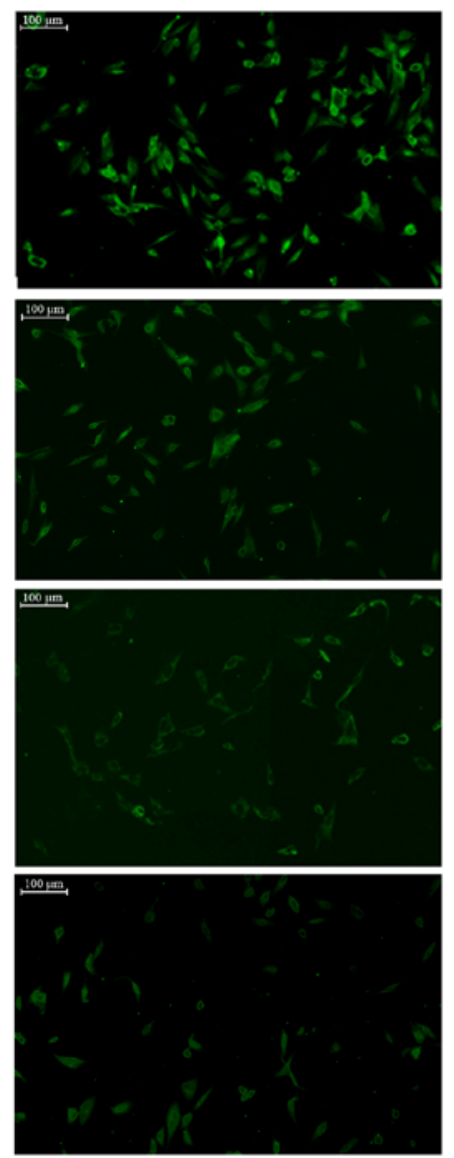

B

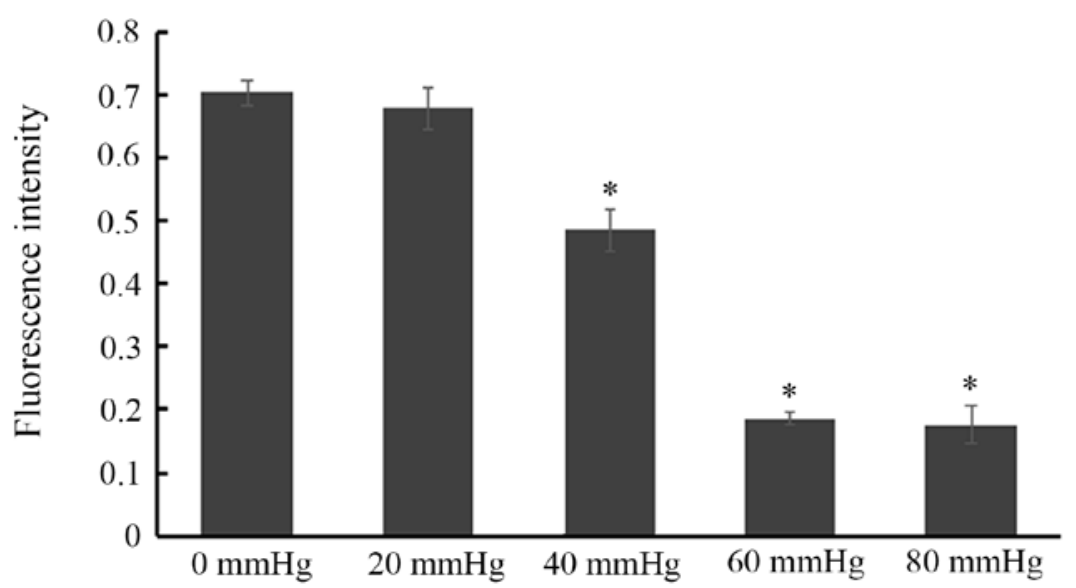

Figure 9. Influence of elevated HP on CREB protein expression in each group of RGCs. (A) Micrographs of immunofluorescence exhibiting CREB expression in RGCs. Green is FITC immunofluorescence staining, and blue is DAPI staining (magnification, x100). (B) Quantification and statistical analysis of fluorescence intensity. Data are presented as the mean \pm standard deviation $(n=3)$. " $\mathrm{P}<0.05$ vs. the $0 \mathrm{mmHg}$ group. HP, hydrostatic pressure; RGC, retinal ganglion cell; CREB, cAMP response element binding protein; FITC, fluorescein isothiocyanate.

morphological changes may be associated with the dysregulation of the NGF pathway. Thus, further research needs to be performed.
RGC apoptosis is the predominant change observed in glaucoma (28). Preliminary studies $(29,30)$ have reported that RGC loss is associated with the downregulation of NGF and 


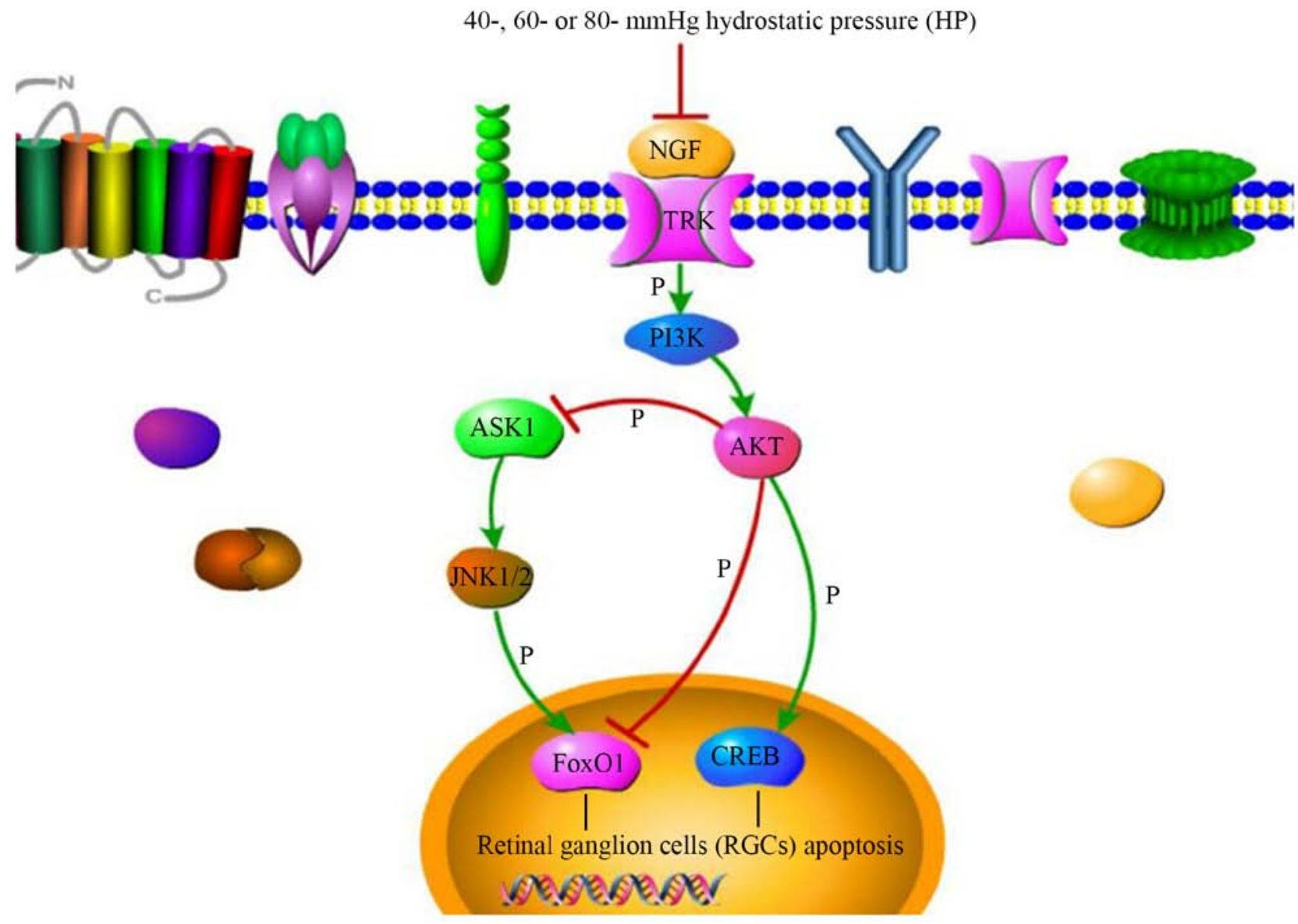

Figure 10. Schematic illustrating the mechanism in which elevated HP induces apoptosis in RGCs through the regulation of the NGF signalling pathway. The protein and mRNA expression level of NGF were decreased in RGCs exposed to HP levels of 40, 60 and $80 \mathrm{mmHg}$ HP; the binding of NGF to TRK receptors activate the PI3K/AKT signalling pathway. When AKT is activated by NGF-stimulated phosphorylation, it may influence RGC apoptosis in three ways. First, it may phosphorylate the target of FoxO1 to mediate cell fate decisions by regulating apoptosis. Second, AKT may phosphorylate ASK1 and reduce its activity; the kinase JNK1/2, downstream of ASK1, phosphorylates and activates FoxO1 protein, resulting in cell apoptosis. Third, the decrease in NGF may trigger reduced phosphorylation of AKT and CREB to induce RGC apoptosis. HP, hydrostatic pressure; RGC, retinal ganglion cell; NGF, nerve growth factor; AKT, protein kinase B; ASK1, apoptosis signal-regulating kinase 1; FoxO1, forkhead box O1; CREB, cAMP response element binding protein; JNK1/2, c-Jun $\mathrm{N}$-terminal kinase 1/2; PI3K, phosphoinositide-3 kinase; TRK, tropomyosin receptor kinase.

NGF receptor expression in the retina, in contrast, treatment with NGF may substantially alleviate the damage induced by glaucoma. The binding of NGF to tropomyosin receptor kinase receptors activates the phosphoinositide-3 kinase/AKT signalling pathway, which is indispensable for maintaining the balance between neuronal life and death $(31,32)$. When AKT is activated by NGF-stimulated phosphorylation, it phosphorylates multiple targets to promote cell survival (33). Although the above experiments revealed the association of NGF and AKT to the loss of RGCs in a rat model of glaucoma, there is no direct evidence to indicate whether they exert the same effects in RGCs with HIOP-induced damage. In the present study, it was revealed that NGF and AKT were closely associated with in vitro RGC apoptosis induced by $\mathrm{HP}$ of 40, 60 and $80 \mathrm{mmHg}$. In addition, downstream of NGF/AKT, ASK1/FoxO1 and CREB have important functions in cell apoptosis. Forkhead box proteins, including FoxO1, are among the targets of AKT and may mediate cell fate decisions by regulating proliferation, differentiation and migration, in addition to apoptosis and survival $(7,34)$. Dysregulation and mutation of forkhead box proteins, including FoxO1, frequently cause human genetic diseases, including glaucoma and tumorigenesis $(35,36)$. Similarly, ASK1 has been reported to be phosphorylated by AKT at serine 83, which reduces its activity $(37,38)$. Studies by Harada et al $(39,40)$ and Katome et al (11) have revealed that the deletion of the ASK1 gene prevented RGC death in a variety of mouse models of glaucoma. The kinase c-Jun N-terminal kinase 1/2, downstream of ASK1, may phosphorylate and activate FoxO1 protein, resulting in cell apoptosis (41). On the other hand, Phan et al (42) had reported that negletein together with NGF enhanced the phosphorylation of AKT and CREB, helping to protect neurons from cell death and promoting neuritogenesis in serum-deprived PC12 cells. In the present study, the increased expression levels of ASK1 and FoxO1 were observed in RGCs exposed to 40, 60 and $80 \mathrm{mmHg}$ HP. CREB, another downstream target of NGF/AKT, had reduced protein and mRNA expression levels in RGCs exposed to HP levels of 40, 60 and $80 \mathrm{mmHg}$, and there were also trends toward decreased protein and mRNA expression levels of NGF and AKT. Interesting, taking $0 \mathrm{mmHg}$ as the baseline, it was revealed that the changes in the protein and mRNA expression levels of CREB, part of the NGF/AKT/CREB pathway, were substantially larger compared with those in ASK1 or FoxO1 
of the NGF/ASK1/FoxO1 pathway from HP values of 40 to $80 \mathrm{mmHg}$. This implies that the NGF/AKT/CREB pathway may serve a notable role in the apoptosis of RGCs exposed to HP values of 40 to $80 \mathrm{mmHg}$, as presented in Fig. 10 .

In conclusion, the observations of the present study suggest that HPs of 40, 60 and $80 \mathrm{mmHg}$ may induce apoptotic morphological changes and increase the apoptosis rate of RGCs in vitro. Regulation of the NGF/ASK1/FoxO1 and NGF/AKT/CREB pathways may be notable mechanisms resulting in RGC apoptosis upon exposure to elevated HP. In addition, the NGF/AKT/CREB pathway may be the primary mechanism of apoptosis in RGCs exposed to elevated HP in vitro. Therefore, it would be worthwhile further investigating the underlying mechanisms in order to extend present understanding of RGC apoptosis under HIOP. The results of the present study provide novel evidence for the molecular mechanisms of RGC apoptosis under elevated HP and pave the way for discovering novel therapeutic methods for patients with glaucoma.

\section{Acknowledgements}

The authors would like to thank the Ophthalmic Laboratory of the Hospital of Chengdu University of Traditional Chinese Medicine for the use of its laboratory and equipment and to Professor Junguo Duan and Professor Xuejing Lu of the Chengdu University of Traditional Chinese Medicine for their help in experimental research.

\section{Funding}

The present study was supported by the National Natural Science Foundation of China (grant no. 81373695).

\section{Availability of data and materials}

The datasets used and/or analysed during the present study are available from the corresponding author on reasonable request.

\section{Authors' contributions}

XL designed the present study and approved this submission. HL and WW performed the experiments, and wrote the manuscript. CH, ZZ, MY and XYL collected and analyzed the data, and revised the manuscript. All authors read and approved the final version of the manuscript.

\section{Ethics approval and consent to participate}

The present study was ethically approved by the Ethics Committee for Animal Research of Chengdu University of Traditional Chinese Medicine (Chengdu, China).

\section{Patient consent for publication}

Not applicable.

\section{Competing interests}

The authors declare that they have no competing interests.

\section{References}

1. Tham YC, Li X, Wong TY, Quigley HA, Aung T and Cheng CY: Global prevalence of glaucoma and projections of glaucoma burden through 2040: A systematic review and meta-analysis. Ophthalmology 121: 2081-2090, 2014.

2. Zhu Y, Zhang L, Sasaki Y, Milbrandt J and Gidday JM: Protection of mouse retinal ganglion cell axons and soma from glaucomatous and ischemic injury by cytoplasmic overexpression of Nmnat1. Invest Ophthalmol Vis Sci 54: 25-36, 2013.

3. Caprioli J: Glaucoma: A disease of early cellular senescence. Invest Ophthalmol Vis Sci 54: ORSF60-67, 2013.

4. Cordeiro MF and Levin LA: Clinical evidence for neuroprotection in glaucoma. Am J Ophthalmol 152: 715-716, 2011.

5. Yan PS, Tang S, Zhang HF, Guo YY, Zeng ZW and Wen Q: Nerve growth factor protects against palmitic acid-induced injury in retinal ganglion cells. Neural Regen Res 11: 1851-1856, 2016.

6. Socodato R, Brito R, Portugal CC, de Oliveira NA, Calaza KC and Paes-de-Carvalho R: The nitric oxide-cGKII system relays death and survival signals during embryonic retinal development via AKT-induced CREB1 activation. Cell Death Differ 21: 915-928, 2014.

7. Zhang X, Tang N, Hadden TJ and Rishi AK: Akt, FoxO and regulation of apoptosis. Biochim Biophys Acta 1813: 1978-1986, 2011.

8. Cheng C, Jiao JT, Qian Y, Guo XY, Huang J, Dai MC, Zhang L, Ding XP, Zong D and Shao JF: Curcumin induces G2/M arrest and triggers apoptosis via FoxO1 signaling in U87 human glioma cells. Mol Med Rep 13: 3763-3770, 2016.

9. Ma Y, Wang X, Peng Y and Ding X: Forkhead box O1 promotes INS1 cell apoptosis by reducing the expression of CD24. Mol Med Rep 13: 2991-2998, 2016.

10. Zhou J, Li H, Li X,Zhang G, Niu Y, Yuan Z, Herrup K, Zhang YW, $\mathrm{Bu} \mathrm{G}, \mathrm{Xu} \mathrm{H}$ and Zhang J: The roles of Cdk5-mediated subcellular localization of FOXO1 in neuronal death. J Neurosci 35: 2624-2635, 2015.

11. Katome T, Namekata K, Guo X, Semba K, Kittaka D, Kawamura K, Kimura A, Harada C, Ichijo H, Mitamura Y and Harada T: Inhibition of ASK1-p38 pathway prevents neural cell death following optic nerve injury. Cell Death Differ 20: 270-280, 2013

12. Sun MM, Wang YC, Li Y, Guo XD, Chen YM and Zhang ZZ: Effect of ATF3-deletion on apoptosis of cultured retinal ganglion cells. Int J Ophthalmol 10: 691-695, 2017.

13. He S, Park YH, Yorio T and Krishnamoorthy RR: Endothelin-mediated changes in gene expression in isolated purified rat retinal ganglion cells. Invest Ophthalmol Vis Sci 56: 6144-6161, 2015.

14. Tok L, Naziroglu M, Uguz AC and Tok O: Elevated hydrostatic pressures induce apoptosis and oxidative stress through mitochondrial membrane depolarization in PC12 neuronal cells: A cell culture model of glaucoma. J Recept Signal Transduct Res 34: 410-416, 2014.

15. Livak KJ and Schmittgen TD: Analysis of relative gene expression data using real-time quantitative PCR and the 2(-Delta Delta C(T)) method. Methods 25: 402-408, 2001.

16. Ohashi T, Sugaya Y, Sakamoto N and Sato M: Hydrostatic pressure influences morphology and expression of VE-cadherin of vascular endothelial cells. J Biomech 40: 2399-2405, 2007.

17. Li Y, Chen YM, Sun MM, Guo XD, Wang YC and Zhang ZZ: Inhibition on apoptosis induced by elevated hydrostatic pressure in retinal ganglion cell-5 via laminin upregulating beta1-integrin/ Focal adhesion kinase/protein kinase B signaling pathway. Chin Med J (Engl) 129: 976-983, 2016.

18. Zhang SH, Gao FJ, Sun ZM, Xu P, Chen JY, Sun XH and Wu JH: High pressure-induced $\mathrm{mtDNA}$ alterations in retinal ganglion cells and subsequent apoptosis. Front Cell Neurosci 10: 254, 2016.

19. Guo L, Moss SE, Alexander RA, Ali RR, Fitzke FW and Cordeiro MF: Retinal ganglion cell apoptosis in glaucoma is related to intraocular pressure and IOP-induced effects on extracellular matrix. Invest Ophthalmol Vis Sci 46: 175-182, 2005

20. Miao H, Crabb AW, Hernandez MR and Lukas TJ: Modulation of factors affecting optic nerve head astrocyte migration. Invest Ophthalmol Vis Sci 51: 4096-4103, 2010.

21. Agar A, Li S, Agarwal N, Coroneo MT and Hill MA: Retinal ganglion cell line apoptosis induced by hydrostatic pressure. Brain Res 1086: 191-200, 2006.

22. Wang S, Hu T, Wang Z, Li N, Zhou L, Liao L, Wang M, Liao L, Wang $\mathrm{H}$, Zeng L, et al: Macroglia-derived thrombospondin 2 regulates alterations of presynaptic proteins of retinal neurons following elevated hydrostatic pressure. PLoS One 12: e0185388, 2017. 
23. Osborne A, Aldarwesh A, Rhodes JD, Broadway DC, Everitt C and Sanderson J: Hydrostatic pressure does not cause detectable changes in survival of human retinal ganglion cells. PLoS One 10: e0115591, 2015.

24. Resta V, Novelli E, Vozzi G, Scarpa C, Caleo M, Ahluwalia A, Solini A, Santini E, Parisi V, Di Virgilio F and Galli-Resta L: Acute retinal ganglion cell injury caused by intraocular pressure spikes is mediated by endogenous extracellular ATP. Eur J Neurosci 25: 2741-2754, 2007.

25. Lee JK, Lu S and Madhukar A: Real-Time dynamics of $\mathrm{Ca} 2+$ caspase-3/7, and morphological changes in retinal ganglion cell apoptosis under elevated pressure. PLoS One 5: e13437, 2010.

26. Maeno E, Ishizaki Y, Kanaseki T, Hazama A and Okada Y: Normotonic cell shrinkage because of disordered volume regulation is an early prerequisite to apoptosis. Proc Natl Acad Sci USA 97: 9487-9492, 2000.

27. Mnich K, Carleton LA, Kavanagh ET, Doyle KM, Samali A and Gorman AM: Nerve growth factor-mediated inhibition of apoptosis post-caspase activation is due to removal of active caspase-3 in a lysosome-dependent manner. Cell Death Dis 5: e1202, 2014

28. Rokicki W, Dorecka M and Romaniuk W: Retinal ganglion cells death in glaucoma-mechanism and potential treatment. Part I. Klin Oczna 109: 349-352, 2007 (In Polish).

29. Colafrancesco V, Parisi V, Sposato V, Rossi S, Russo MA, Coassin M, Lambiase A and Aloe L: Ocular application of nerve growth factor protects degenerating retinal ganglion cells in a rat model of glaucoma. J Glaucoma 20: 100-108, 2011.

30. Wang H, Wang R, Thrimawithana T, Little PJ, Xu J, Feng ZP and Zheng $\mathrm{W}$ : The nerve growth factor signaling and its potential as therapeutic target for glaucoma. Biomed Res Int 2014: 759473, 2014

31. Andjelkovic M, Suidan HS, Meier R, Frech M, Alessi DR and Hemmings BA: Nerve growth factor promotes activation of the alpha, beta and gamma isoforms of protein kinase B in PC12 pheochromocytoma cells. Eur J Biochem 251: 195-200, 1998.

32. Crowder RJ and Freeman RS: Phosphatidylinositol 3-kinase and Akt protein kinase are necessary and sufficient for the survival of nerve growth factor-dependent sympathetic neurons. J Neurosci 18: 2933-2943, 1998.

33. Franke TF, Hornik CP, Segev L, Shostak GA and Sugimoto C: PI3K/Akt and apoptosis: Size matters. Oncogene 22: 8983-8998, 2003.
34. Tzivion G, Dobson M and Ramakrishnan G: FoxO transcription factors; Regulation by AKT and 14-3-3 proteins. Biochim Biophys Acta 1813: 1938-1945, 2011.

35. Wierstra I: FOXM1 (Forkhead box M1) in tumorigenesis: Overexpression in human cancer, implication in tumorigenesis, oncogenic functions, tumor-suppressive properties, and target of anticancer therapy. Adv Cancer Res 119: 191-419, 2013.

36. Hannenhalli S and Kaestner KH: The evolution of Fox genes and their role in development and disease. Nat Rev Genet 10: 233-240, 2009.

37. Kim AH, Khursigara G, Sun X, Franke TF and Chao MV: Akt phosphorylates and negatively regulates apoptosis signal-regulating kinase 1. Mol Cell Biol 21: 893-901, 2001.

38. Yuan ZQ, Feldman RI, Sussman GE, Coppola D, Nicosia SV and Cheng JQ: AKT2 inhibition of cisplatin-induced JNK/p38 and Bax activation by phosphorylation of ASK1. Implication of AKT2 In chemoresistance. J Biol Chem 278: 22832-23840, 2003.

39. Harada C, Namekata K, Guo X, Yoshida H, Mitamura Y, Matsumoto Y, Tanaka K, Ichijo H and Harada T: ASK1 deficiency attenuates neural cell death in GLAST-deficient mice, a model of normal tension glaucoma. Cell Death Differ 17: 1751-1759, 2010.

40. Harada C, Nakamura K, Namekata K, Okumura A, Mitamura Y, Iizuka Y, Kashiwagi K, Yoshida K, Ohno S, Matsuzawa A, et al: Role of apoptosis signal-regulating kinase 1 in stress-induced neural cell apoptosis in vivo. Am J Pathol 168: 261-269, 2006.

41. Essers MA, Weijzen S, de Vries-Smits AM, Saarloos I, de Ruiter ND, Bos JL and Burgering BM: FOXO transcription factor activation by oxidative stress mediated by the small GTPase Ral and JNK. EMBO J 23: 4802-4812, 2004.

42. Phan CW, Sabaratnam V, Bovicelli P, Righi G and Saso L: Negletein as a neuroprotectant enhances the action of nerve growth factor and induces neurite outgrowth in PC12 cells. Biofactors 42: 591-599, 2016.

This work is licensed under a Creative Commons Attribution-NonCommercial-NoDerivatives 4.0 International (CC BY-NC-ND 4.0) License. 